\title{
Treatment of alcohol dependence in patients with co-morbid major depressive disorder - predictors for the outcomes with memantine and escitalopram medication
}

\author{
Leea H Muhonen ${ }^{1,6}$, Jari Lahti ${ }^{5}$, David Sinclair ${ }^{1}$, Jouko Lönnqvist ${ }^{1,2,3}$ and \\ Hannu Alho*1,4
}

Address: ${ }^{1}$ National Public Health Institute, Department of Mental Health and Alcohol Research, Finland, ${ }^{2}$ Department of Psychiatry, University of Helsinki, Finland, ${ }^{3}$ Helsinki University Central Hospital, Finland, ${ }^{4}$ Research Unit of Substance Abuse Medicine, University of Helsinki and Helsinki University Central Hospital, Finland, ${ }^{5}$ Department of Psychology, University of Helsinki, Finland and ${ }^{6}$ Helsinki City Health Care Center, Finland

Email: Leea H Muhonen - leea.muhonen@ktl.fi; Jari Lahti - jari.lahti@helsinki.fi; David Sinclair - david.sinclair@ktl.fi; Jouko Lönnqvist - jouko.lonnqvist@ktl.fi; Hannu Alho* - hannu.alho@ktl.fi

* Corresponding author

Published: 3 October 2008

Substance Abuse Treatment, Prevention, and Policy 2008, 3:20 doi:I0.1 186/1747-597X-3-20
Received: I July 2008

Accepted: 3 October 2008

This article is available from: http://www.substanceabusepolicy.com/content/3/1/20

(c) 2008 Muhonen et al; licensee BioMed Central Ltd.

This is an Open Access article distributed under the terms of the Creative Commons Attribution License (http://creativecommons.org/licenses/by/2.0), which permits unrestricted use, distribution, and reproduction in any medium, provided the original work is properly cited.

\begin{abstract}
Background: Alcohol dependence comorbid with major depressive disorder poses a major challenge in the clinical setting. The results in the treatment with selective serotonin re-uptake inhibitors have been conflicting. Thus, we compared in alcohol-dependent patients with co-morbid major depressive disorder the selective serotonin re-uptake inhibitor escitalopram to a compound that acts on different transporter system and may reduce craving, the glutamate receptor antagonist memantine.

Methods: Eighty alcohol-dependent patients comorbid with major depressive disorder in municipal alcohol clinics were randomized I:I to receive memantine $20 \mathrm{mg}$ or escitalopram $20 \mathrm{mg}$ in a double-blind manner. During the 26-week study period patients continued their routine treatment at the clinics. Abstinence was not required but encouraged. The patients attended visits weekly during the first month, and then at 3 and at 6 months. Outcome measures were Alcohol Use Disorders Identification Test (AUDIT), Obsessive Compulsive Drinking Scale (OCDS) and Drinking Diary.

Results: The completion rate was high in both groups, especially among the patients who had been abstinent at the beginning of the study. However, among those patients who were not abstinent at baseline, $47 \%$ in both groups discontinued the study. Numbers of abstinent days were high in both groups throughout the study. Alcohol consumption measured by the AUDIT QF (quantity-frequency) score was significantly reduced in both groups, as was the craving for alcohol measured by the OCDS. Early age at first alcohol intoxication predicted poor treatment outcomes in patients treated with escitalopram, and the same was seen with the early onset of the first depressive episode. The same predictive effects were not found in patients treated with memantine.

Conclusion: Our results indicate that both memantine and escitalopram are useful adjunct medications for the treatment of alcohol dependence co-morbid with major depression. Memantine was at least as effective with regard to drinking as escitalopram. We believe that a direct comparison of memantine, with the commonly used escitalopram, can provide useful information for clinicians on the treatment of alcohol dependency co-morbid with MDD.
\end{abstract}

Trial registration: ClinicalTrials.gov Identifier \# NCT00368862 


\section{Background}

The lifetime prevalence of alcohol dependence as well as co-morbidity with depressive disorders is high. For example, the lifetime prevalence of alcoholism was $5.4 \%$ in the United States among individuals over the age of 18 years according to the National Comorbidity Survey Replication (NCS-R)[1]. Among these alcohol-dependent patients, co-morbidity with depressive disorders was $24.3 \%$ in men and $48.5 \%$ in women [2]. Alcohol-dependent patients who are co-morbid for major depressive disorder (MDD) constitute a patient group whose pharmaceutical treatment has been particularly difficult [3].

It has been proposed that SSRIs are most beneficial for the treatment of alcohol dependence $[17,18]$. However, the results are inconsistent. Some studies supported the efficacy of zimilidine and citalopram in alcoholics [18-20]. In alcoholism without depression, SSRIs have shown positive results in cases of less severe drinking [5,21]. In some studies SSRIs were found even to be worse than placebo $[22,23]$ especially when treating early onset (Type B, Type II) subtypes of alcoholics $[24,25]$. Treatment with SSRIs for alcohol dependence with co-morbid major depressive disorder (MDD), however, has generally produced positive results $[11,12,26]$. Escitalopram, the S-enantiomer of citalopram, is the most selective of the SSRI antidepressants [27]. It is now widely used for the treatment of depression [20]. In a recent review escitalopram was found to have the highest efficacy among antidepressants in the treatment of severe depression [28] but there are no studies on escitalopram in the treatment of MDD comorbid with alcohol dependence.

Acamprosate is a weak NMDA modulator which acts as an antagonist at the mGluR5 metabotropic glutamate receptor [29]. Acamprosate is approved in many countries for the treatment of alcohol dependence [30] although some recent studies $[31,32]$ have not found significant benefits.

Memantine is a non-competitive ionotropic NMDA receptor blocker. It is FDA approved for the treatment of moderate to severe Alzheimer's disease [33]. Memantine has been shown to block ethanol-induced up-regulation of NMDA receptors [34]. Rat studies have shown that memantine may reduce alcohol craving [35-39]. Recent clinical studies show that memantine may suppresses the craving for alcohol in moderate drinkers when deprived, but not when drinking [40]. In recovering alcoholdependent patients memantine seemed to reduce craving [41], while in actively drinking alcohol-dependent nondepressive patients, memantine did not reduce craving or alcohol consumption [42]. The studies of memantine in the treatment of depression are rare: when treated therapy-resistant depressive patients, Zarate did not find any recovering [43], while in our recent study, memantine was comparable with escitalopram in the treatment of major depression comorbid with alcohol dependence [44]. We hypothesized that the NMDA receptor antagonist memantine may reduce also craving and alcohol consumption in depressive alcoholics. The aim of this study was to compare effects of NMDA receptor antagonist memantine to escitalopram on alcohol consumption, in a natural sample of treatment-seeking alcohol-dependent patients (both actively drinking and recovering) with comorbid MDD. The possible predictors for treatment outcomes were studied also.

\section{Methods}

\section{Study participants}

Men and women aged 26 to 65 years who were voluntarily seeking outpatient treatment for alcohol problems at three Helsinki municipal Alcohol-clinics (A-clinics). Patients with a history of heavy drinking (averaging five or more daily drinks for men and four or more daily drinks for women) for at least ten years, significant depression defined by the Beck Depression Inventory II (BDI-II > 16), and who were interested in voluntarily taking part in the study were recommended by their A-clinic doctor or social worker therapist to be interviewed and screened by the study physician. The patients were interviewed by the study doctor (psychiatrist LM) applying the Structured Clinical Interview for DSM- IV (SCID) and were required to meet the criteria of both alcohol dependence and MDD according to DSM-IV-TR. Abstinence was not required but encouraged. The time since the last prior inpatient detoxification had to be at least four weeks. In addition, the eligible patients had to be currently in a depressive episode lasting for more than two weeks. The exclusion criteria included other substance use dependence screened by urine test (amphetamine, benzodiazepines, cocaine, tetrahydrocannabinol and opiates, schizophrenia or other psychotic disorder, and bipolar I and II disorder, acute risk of suicide, pregnancy or breastfeeding, a severe untreated somatic problem, or a serious dysfunction of the liver (aspartate aminotransferase [AST] and alanine aminotransferase [ALT] > 200), and mental disability. Other medications prescribed by participants' physicians were allowed, with the exception of other antidepressants. All patients were Caucasian, and 55\% were men. There were no significant differences between the groups in either their demographic characteristics or their initial alcohol and depressive measures [44]. The mean length of the present depressive period was 35 months. Current alcohol use was reported by 17 patients $(43.6 \%)$ in the memantine group and 17 (42.5\%) in the escitalopram group. The number of A-clinic visits (psychosocial counseling) during the study period was similar: in the memantine group $7.7 \pm 8.8$ (mean $\pm \mathrm{SD}$ ) and in the escitalopram group 7.1 \pm 9.2. [44]. 
All 58 subjects who completed the study attended all appointments and showed at least $80 \%$ compliance based on tablet counts. The average consumption (mg) of medication did not differ between the two medication groups: during the first 12 weeks, for memantine $17.4 \pm 0.5 \mathrm{mg}$ and for escitalopram $16.9 \pm 0.6 \mathrm{mg}$; and during weeks $13-$ 26 , for memantine $17.4 \pm 0.6 \mathrm{mg}$ and for escitalopram $15.9 \pm 0.8 \mathrm{mg}$.

\section{Ethics}

The study was approved by the independent Hospital District of Helsinki and Uusimaa, Ethical Committee (permission 22/2004) and the Finnish National Agency of Medicine (KL\# 87/2004). The study was conducted according the ICH Guidelines for Good Clinical Practice and the 1964 Declaration of Helsinki. The study was registered on the National Public Health study registry in March, 2005 (172-9), and the ClinicalTrials.gov Identifier (trial \# NCT00368862). All patients had to be able to read and understand the patient information sheet and sign the informed consent. All participants were free to stop the study medication whenever they wanted. The patients were not paid or otherwise reimbursed for participation.

\section{Study design}

Eighty-nine patients were initially screened. A screening interview (SCID) was conducted to confirm the diagnoses of MDD and alcohol dependence. Patients completed questionnaires including the Obsessive-Compulsive Drinking Scale (OCDS [45]) and the Alcohol Use Disorders Identification Test (AUDIT) [46]. AUDIT-QF [47], and AUDIT-3 [48] were used for a detailed drinking analysis. The recording of alcohol consumption during the 26week treatment period was done with a personal drinking diary for all days, including abstinent days [49].

All patients meeting the inclusion criteria were randomly assigned to the memantine or escitalopram group using a $1: 1$ ratio $(\mathrm{n}=40+40)$. Eligible patients received orally either $20 \mathrm{mg}$ /day escitalopram or $20 \mathrm{mg} /$ day memantine. The starting dose was $5 \mathrm{mg} /$ day for both drugs and was increased at weekly intervals by $5 \mathrm{mg} /$ day to $20 \mathrm{mg} /$ day. Patients were instructed to take the study medication in the morning. Patients were permitted to telephone the study physician at any time. If the patient did not appear at a scheduled visit, a new appointment was offered.

During the 26-week treatment period, the patients returned to the study site at weeks $1,2,4,12 \pm 2$, and 26 \pm 2 for data collection and for medication checking and dispensing. At each visit, the drinking diary and the study medication intake since the previous visit were recorded from the medication diary. The study medication was ensured by pill count from the returned blister-packs.
Outcomes were recorded on specific weeks: OCDS (weeks 0, 4, 12 and 26); AUDIT (week 0, 12 and 26, the later ones modified to report the events in the previous month). Clinical laboratory tests (MCV, AST, ALT, CDT, and GGT) were taken at the beginning of the study and were repeated at weeks 4,12 , and 26 , to ensure the safety of the medication. No breath or blood test for alcohol was performed, but if the patient was obviously intoxicated, a new appointment was offered. The study was monitored by an independent organization, Medikalla Oy, Medfiles, Turku.

\section{Statistical analysis}

All primary and secondary outcome statistical analysis was performed by an independent source (Medikalla Oy, MedFiles, Turku). All statistical evaluation utilized SAS Procedures in SAS ${ }^{\circledast}$ system for Windows (Version 8.2), SAS-institute, Espoo, Finland.

Intent-to-treat sample, which included all randomized patients including two patients who discontinued early in the study and reported, taking no medication, were used in all tables and analyses. Descriptive statistics were calculated for all variables. Categorical variables were presented in frequencies tables (number of cases and percentages) by treatment. The numerical variables were tabulated by treatment. Baseline measures were analyzed by logistics regression or analysis of variance. All repeated dependent measures (drinking diary, OCDS, AUDIT, laboratory tests), were analyzed with analysis of variance for repeated measures (ANOVA) when treatment, time, and treatment * time interaction were in the model (PROC MIXED in $\mathrm{SAS}^{\circledast}$ ) and responses to the specific question (Has your alcohol use diminished during the study?) were analyzed by logistic regression (PROG LOGOSTIC in SAS ${ }^{\circledR}$ ).

Furthermore, predictors of treatment response by medication were analyzed with multiple linear regression analyses by adjusting for the baseline OCDS and AUDIT scores.

\section{Results}

The drop out ratio was similar in the two groups: 11 out of 40 patients $(27.5 \%)$ discontinued the study before the end of the 26-week period in both the memantine and the escitalopram groups. Two patients in both treatment groups $(6.9 \%)$ used disulfiram, and one patient in both groups (3.4\%) used a mood stabilizer.

\section{Alcohol consumption}

The baseline AUDIT and alcohol use histories are similar in both groups (Table 1). AUDIT scores decreased (Fig. 1) from baseline in both groups, from $27.4 \pm 7.1$ to $14.3 \pm$ 9.9 in the memantine group and from $28.4 \pm 6.4$ to 17.6 \pm 10.4 in the escitalopram group. The overall reduction was highly significant $(F[2.77]=48.42, p<.0001)$ in both 
Table I: Demographic backgrounds.

\begin{tabular}{lcc}
\hline \multicolumn{1}{c}{ Variable } & Memantine $(\mathbf{n}=\mathbf{4 0})$ & Escitalopram $(\mathbf{n}=\mathbf{4 0})$ \\
\hline Age (years, mean \pm SD) & $47.5( \pm 8.3)$ & $47.9( \pm 8.3)$ \\
Gender, male (n, \%) & $23(57.5)$ & $21(52.5)$ \\
First alcohol intoxication, (age, mean \pm SD) & $15.3( \pm 3.8)$ & $15.4( \pm 2.3)$ \\
Onset of regular use of alcohol (age, mean \pm SD) & $20.7( \pm 6.7)$ & $20.5( \pm 6.3)$ \\
Onset of alcohol abuse (age mean \pm SD) & $29.5( \pm 8.1)$ & $28.3( \pm 8.3)$ \\
Onset of alcohol dependence (age, mean \pm SD) & $30.6( \pm 8.3)$ & $29.1( \pm 8.5)$ \\
Audit baseline (mean \pm SD) & $27.4( \pm 1.1)$ & $28.4( \pm 1.0)$ \\
No abstinence before study initiation (n, \%) & $17(43.6)$ & $17(42.5)^{*}$ \\
Alcohol problems among relatives (n, \%), & $31(79.5)^{*}$ & $30(76.9)^{*}$ \\
Montgomery-Asberg depression rating scale (MADRS) baseline scores & $25.8( \pm 4.4)$ & $26.8( \pm 4.1)$ \\
First depressive episode (age, mean \pm SD) & $27.8( \pm 12.3)$ & $24.2( \pm 13.0)$ \\
Total number of depressive episodes (mean \pm SD) & $10.0( \pm 7.1)$ & $9.6( \pm 9.0)$
\end{tabular}

There were no significant differences between the groups on any of the baseline socio-demographic background measures.

*missing information in one patient

groups combined. The treatment by time interaction was not significant $(F[2.77]=1.19, p=0.31)$.

Alcohol consumption measured by the AUDIT QF (quantity-frequency) score was significantly reduced in both groups: in the memantine group from $6.2 \pm 1.7$ to $4.1 \pm$ 2.5 and from $6.1 \pm 1.7$ to $4.3 \pm 2.3$ in the escitalopram group $(F[2.77]=23.53, p<.0001)$. The treatment by time interaction was not significant $(F[2.77]=1.58, p=0.21)$. The number of heavy drinking days measured by the AUDIT-3 score was also diminished significantly in both groups: for the memantine group from $2.9 \pm 1.1$ to $1.8 \pm$ 1.3 and from $3.1 \pm 1.0$ to $2.4 \pm 1.3$ for the escitalopram

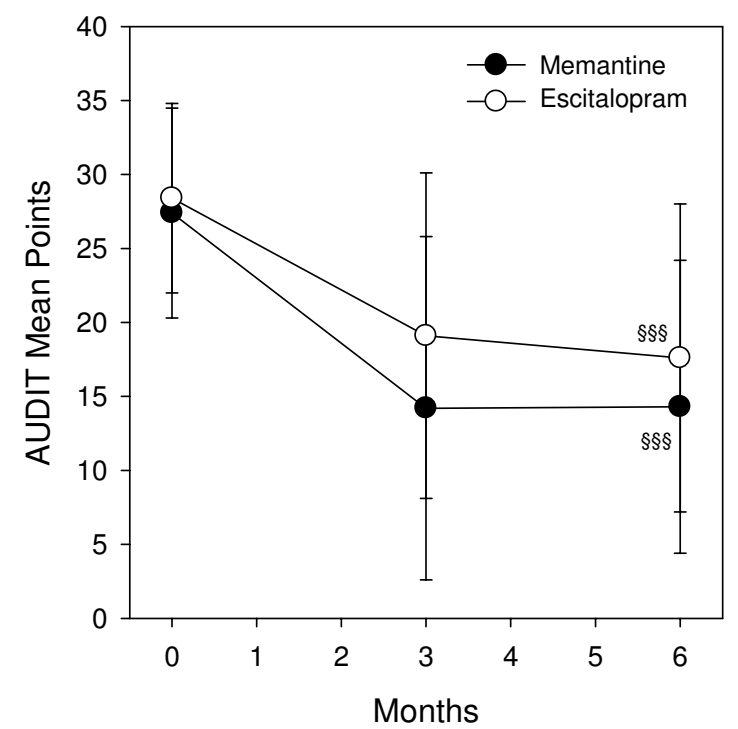

Figure I

Change in alcohol use measured by the AUDIT scores. $§ \S \S S i g n i f i c a n t$ reduction from base values prior to treatment, $\mathrm{p}<.000 \mathrm{I}, \pm \mathrm{SD}$. group $(F[2.77]=20.29, p>.0001)$. The treatment by time interaction was not significant $(F[2.77]=1.37, p=0.27)$.

The number of abstinent days per week was high for both groups throughout the study. The treatment by time interaction in the number of abstinent days per week was not significant $(F[2.74]=0.07, p=0.93)$ (Figure 2$)$. The mean alcohol intake including abstinent days was $15.0 \pm 2.6 \mathrm{~g}$ per day for the memantine group and $21.1 \pm 3.6 \mathrm{~g}$ per day for the patients on escitalopram, with no significant difference between the groups $(F[1.74]=1.94, p=0.17)$.

When questioned at the end of the intervention, $68.9 \%$ of the patients in the memantine group reported their alcohol use had decreased while $62.1 \%$ of the patients in the escitalopram group reported a decrease.

\section{Indicators of craving for alcohol}

The OCDS total scores (Fig. 3) decreased in the memantine group from $18.8 \pm 6.9$ to $10.6 \pm 7.2$ and in the escitalopram group from $20.4 \pm 4.9$ to $12.8 \pm 8.6$. The overall reduction was highly significant $(F[3.77]=25.76, p<$ $.0001)$ in both groups combined. The treatment by time interaction in the OCDS was not significant $(F[3.77]=$ $0.69 ; p=0.56)$.

In both groups, the mean serum concentrations of AST, ALT, GGT, and CDT were within normal limits, and there were no significant changes during the treatment period or any significant differences between the groups. The adverse events during the study are published in our previous article [44]. There was no significant difference in reporting adverse events between the medication groups.

\section{Predictors of the treatment outcomes}

In general, those patients who were abstinent at the beginning of treatment were more likely to complete the treatment than those who were still drinking at the beginning 


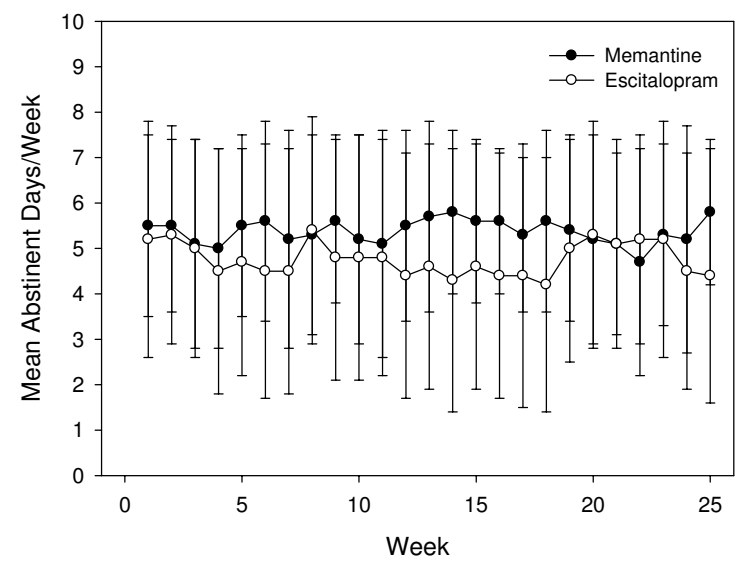

Figure 2

Mean number of abstinent days per week. No statistically significant difference between the treatment groups in mean number of days \pm SD.

$\left(\chi^{2}=6.51, d f=1, p=0.011\right)$. This relationship was highly significant in the patients treated with memantine $\left(\chi^{2}=\right.$ $7.25, d f=1, p=0.007)$ : 8 of the 11 who dropped out were among the $17(47.1 \%)$ who were active drinkers at the baseline. The relationship was in the same direction in the escitalopram group but failed to reach statistical significance $\left(\chi^{2}=0.901, d f=1, p=0.343\right)$.

We tested by multiple linear regression analyses whether age at onset of depression and age at first alcohol intoxi-

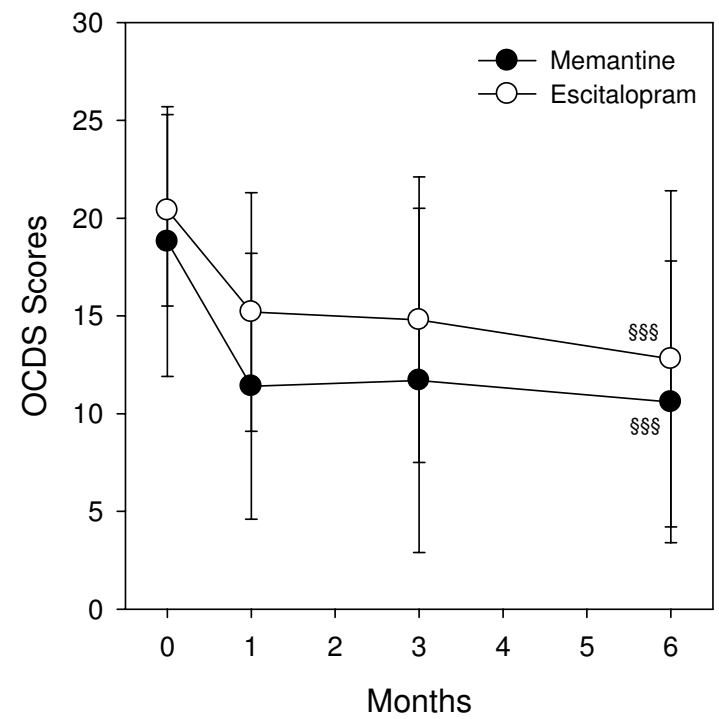

Figure 3

Change in alcohol graving measured by the OCDS scores. $\S \S \S$ significant reduction from base values prior to treatment, $\mathrm{p}<.000 \mathrm{I}, \pm \mathrm{SD}$. cation predicted change during the six month treatment in the OCDS and the AUDIT scores. Age at onset of depression predicted differently change in the OCDS in the escitalopram group compared with the memantine group $\left(R^{2}\right.$ change for interaction term $=0.05$; $p$ for treatment by age at onset of depression interaction $=0.05$ ). In the escitalopram group, earlier onset of depression predicted less change in the OCDS scores during the six months $(B=-$ $0.31,95 \% \mathrm{CI}=-0.53$ to $-0.09, p=0.008)$ whereas in the memantine group no such association existed $(B=-0.02$, $95 \% \mathrm{CI}=-0.22$ to $0.17, p=0.81)$. There were no differences between the medication groups in the association between age at onset of depression and change in the AUDIT $\left(R^{2}\right.$ change for interaction term $=0.02 ; p$ for interaction $=0.21$ ) or in the association between age at first alcohol intoxication and change in the OCDS and the AUDIT $\left(R^{2}\right.$ change for interaction term $<0.022$; $p$-values for interactions $>0.21)$. Neither did age at onset of depression predict change in the AUDIT $(B=-0.16,95 \% \mathrm{CI}=-$ 0.37 to $0.05, p=0.12$ ) or age at first alcohol intoxication predict change in the OCDS $(B=-0.68,95 \% \mathrm{CI}=-1.41$ to $0.05, p=0.07)$ and the AUDIT $(B=-0.24,95 \% \mathrm{CI}=-1.62$ to $1.13, p=0.72$ ) in the subjects when both treatment groups were combined.

\section{Discussion}

Citalopram and escitalopram have been used in the treatment of alcohol dependence especially when co-morbid with major depressive disorder. Treatment outcomes with other SSRIs have not been consistent [3,15,26,50-53]. In our study, both memantine and escitalopram patients reported reduced alcohol craving and consumption, and patient compliance was good. However, the two study groups did not differ in alcohol craving, obsessive thoughts of drinking, compulsive drinking, alcohol consumption, maintaining abstinence, and number of abstinent days per week. Our study corroborates a recent study by Krupitsky et al. [41], who reported that memantine reduced alcohol cue-induced craving in recovering alcoholics.

Few possible predictive elements for the treatment of alcohol dependence comorbid with major depressive disorder with either escitalopram or memantine were observed. The abstinence at the beginning of the treatment predicted more likely the continuing of the treatment, especially in the memantine group. Evans et al. [42] found no effect of memantine in patients who were actively drinking at the beginning of treatment, which may explain our findings that such patients had a higher dropout rate than those who were abstinent at the start of treatment. Other predictor observed was the early age at onset of the first depressive episode, which leads to poor treatment outcome with escitalopram but not with memantine. How- 
ever, due to multiple testing without a priori hypothesis, this difference should be interpreted with caution.

Our study has several limitations. It is a comparative study of two medications and is limited by the absence of a placebo group. Both treatment groups improved significantly and a placebo-effect could be significant in both groups, as has been observed in earlier studies [52]. Spontaneous recovery and intermittent periods of lower alcohol intake are of typical in alcohol dependence $[54,55]$. Therefore, we cannot determine whether the overall improvement in the present study was due to the medications, and our interpretations are limited to comparisons between memantine and escitalopram. Detoxification and a certain period of abstinence could influence the results.

Another limitation is the rather small number of patients, which may have been too low to detect a significant difference between the treatments. Socio-demographic indicators correspond well to those generally found among patients treated at Finnish A-clinics [56], suggesting that the present material represents a relatively unbiased sample. The only difference observed was the higher percentage of women, which can probably be attributed to the inclusion criterion of major depression. We did not attempt to distinguish between patients with primary depressive disorders and substance-induced depression. This situation corresponds to that at the onset of treatment; it is when the clinician has to decide which medications to prescribe. Our patients were treatment-seeking, so the option of providing no active medication was not accepted by either the treating professionals or the patients.

Our finding may suggest that memantine could be useful treatment for type one alcoholics (early onset) comorbid with depression. The finding that the early onset of the first depressive episode is a negative predictor for escitalopram treatment in alcohol dependence confirms our previous finding on treatment of this comorbidity regarding major depressive disorder in patients with this dual diagnosis [57].

It may be concluded that memantine seems comparable to escitalopram and could be used as well as escitalopram in the treatment of alcohol dependence comorbid with major depression. The results, therefore, warrant further studies of memantine in patients with alcohol dependence comorbid with major depression as well as of predictive signs of treatment outcome. However, because of the small number of study patients and the conventional statistics, the results should be taken with caution.

\section{Competing interests}

The authors declare that they have no competing interests.

\section{Authors' contributions}

LM, JLÖ and HA have made substantial contributions to conception and design, LM and HA for acquisition of data, LM, JLA, DJ and HA analysis and interpretation of data; all authors have been involved in drafting the manuscript or revising it critically for important intellectual content; and all authors have given final approval of the version to be published.

\section{Acknowledgements}

The study was funded by the National Public Health Institute, the Finnish Foundation for Alcohol Research. and Helsinki Health Center Research Fund We thank the personnel of the Annankatu, Töölö, and Malmi A-clinics for their assistance with subject collection; Sirpa Päivinen for the data filing; Petri Hyytiä for graphs; and Henna Ahtinen (Medikalla Oy, Medfiles) for statistical advice and analysis.

\section{References}

I. Kessler RC, Berglund P, Demler O, Jin R, Merikangas KR, Walters EE: Lifetime prevalence and age-of-onset distributions of DSMIV disorders in the National Comorbidity Survey Replication. Arch Gen Psychiatry 2005, 62(6):593-602.

2. Kessler RC, Crum RM, Warner LA, Nelson CB, Schulenberg J Anthony JC: Lifetime co-occurrence of DSM-III-R alcohol abuse and dependence with other psychiatric disorders in the National Comorbidity Survey. Arch Gen Psychiatry 1997, 54(4):3|3-32|.

3. Pettinati HM: Antidepressant treatment of co-occurring depression and alcohol dependence. Biol Psychiatry 2004, 56(I0):785-792.

4. Rounsaville BJ, Dolinsky ZS, Babor TF, Meyer RE: Psychopathology as a predictor of treatment outcome in alcoholics. Arch Gen Psychiatry 1987, 44(6):505-5I3.

5. Pettinati HM, Volpicelli JR, Luck G, Kranzler HR, Rukstalis MR, Cnaan A: Double-blind clinical trial of sertraline treatment for alcohol dependence. J Clin Psychopharmacol 200I, 2 I (2): I 43-I53.

6. Willinger $U$, Lenzinger E, Hornik K, Fischer G, Schonbeck G, Aschauer $\mathrm{HN}$, Meszaros K: Anxiety as a predictor of relapse in detoxified alcohol-dependent patients. Alcohol Alcohol 2002, 37(6):609-6/2.

7. Cloninger CR: A systematic method for clinical description and classification of personality variants. A proposal. Arch Gen Psychiatry 1987, 44(6):573-588.

8. Verheul R, Brink W van den, Geerlings P: A three-pathway psychobiological model of craving for alcohol. Alcohol Alcohol I999, 34(2): 197-222.

9. Spanagel R: Recent animal models of alcoholism. Alcohol Res Health 2000, 24(2): |24-|3|.

10. Virkkunen M, Linnoila M: Serotonin in early onset, male alcoholics with violent behaviour. Ann Med 1990, 22(5):327-331.

II. Naranjo CA, Knoke DM: The role of selective serotonin reuptake inhibitors in reducing alcohol consumption. J Clin Psychiatry 200I, 62(Suppl 20): 18-25.

12. Johnson BA: Role of the serotonergic system in the neurobiology of alcoholism: implications for treatment. CNS Drugs 2004, I 8( I 5): II05-III 8.

13. Kiefer F, Helwig H, Tarnaske T, Otte C, Jahn H, Wiedemann K: Pharmacological relapse prevention of alcoholism: clinical predictors of outcome. Eur Addict Res 2005, I I (2):83-9I.

14. Verheul R, Lehert P, Geerlings PJ, Koeter MW, Brink W van den: Predictors of acamprosate efficacy: results from a pooled analysis of seven European trials including I485 alcoholdependent patients. Psychopharmacology (Berl) 2005, I78(23): $167-173$

15. Cornelius JR, Bukstein O, Salloum I, Clark D: Alcohol and psychiatric comorbidity. Recent Dev Alcohol 2003, 16:36I-374.

16. Cornelius JR, Salloum IM, Thase ME, Haskett RF, Daley DC, JonesBarlock A, Upsher C, Perel JM: Fluoxetine versus placebo in depressed alcoholic cocaine abusers. Psychopharmacol Bull 1998 , 34(I): $|17-| 2 \mid$. 
17. Amit Z, Sutherland EA, Gill K, Ogren SO: Zimeldine: a review of its effects on ethanol consumption. Neurosci Biobehav Rev 1984, 8(I):35-54.

18. Naranjo CA, Sellers EM, Lawrin MO: Modulation of ethanol intake by serotonin uptake inhibitors. J Clin Psychiatry 1986, 47(Suppl): I6-22.

19. Naranjo CA, Bremner KE: Evaluation of the effects of serotonin uptake inhibitors in alcoholics: a review. In Novel Pharmcological Interventions for Alcoholism Edited by: Naranjo CA, Sellers EM. New York: Springer-Verlag; 1992:105-II7.

20. Thase ME: Managing depressive and anxiety disorders with escitalopram. Expert Opin Pharmacother 2006, 7(4):429-440.

21. Tiihonen J, Ryynanen OP, Kauhanen J, Hakola HP, Salaspuro M: Citalopram in the treatment of alcoholism: a double-blind placebo-controlled study. Pharmacopsychiatry 1996, 29(I):27-29.

22. Kranzler HR, Burleson JA, Brown J, Babor TF: Fluoxetine treatment seems to reduce the beneficial effects of cognitivebehavioral therapy in type B alcoholics. Alcohol Clin Exp Res 1996, 20(9): 1534-154I.

23. Chick J, Aschauer H, Hornik K: Efficacy of fluvoxamine in preventing relapse in alcohol dependence: a one-year, doubleblind, placebo-controlled multicentre study with analysis by typology. Drug Alcohol Depend 2004, 74(I):6 I-70.

24. Cloninger CR, Sigvardsson S, Gilligan SB, von Knorring AL, Reich T, Bohman $M$ : Genetic heterogeneity and the classification of alcoholism. Adv Alcohol Subst Abuse 1988, 7(3-4):3-16.

25. Babor TF, Hofmann M, DelBoca FK, Hesselbrock V, Meyer RE, Dolinsky ZS, Rounsaville B: Types of alcoholics, I. Evidence for an empirically derived typology based on indicators of vulnerability and severity. Arch Gen Psychiatry 1992, 49(8):599-608.

26. Cornelius JR, Salloum IM, Ehler JG, Jarrett PJ, Cornelius MD, Perel JM, Thase ME, Black A: Fluoxetine in depressed alcoholics. A double-blind, placebo-controlled trial. Arch Gen Psychiatry 1997, 54(8):700-705.

27. Owens MJ, Knight DL, Nemeroff $C B$ : Second-generation SSRIs: human monoamine transporter binding profile of escitalopram and R-fluoxetine. Biol Psychiatry 200I, 50(5):345-350.

28. Montgomery SA, Baldwin DS, Blier P, Fineberg NA, Kasper S, Lader M, Lam RW, Lepine JP, Moller HJ, Nutt DJ, et al: Which antidepressants have demonstrated superior efficacy? A review of the evidence. Int Clin Psychopharmacol 2007, 22(6):323-329.

29. De Witte P, Littleton J, Parot P, Koob G: Neuroprotective and abstinence-promoting effects of acamprosate: elucidating the mechanism of action. CNS Drugs 2005, I 9(6):5 17-537.

30. Lesch OM, Riegler A, Gutierrez K, Hertling I, Ramskogler K, Semler B, Zoghlami A, Benda N, Walter H: The European acamprosate trials: conclusions for research and therapy. J Biomed Sci 200 I, 8(I):89-95.

31. Soyka M, Roesner S: New pharmacological approaches for the treatment of alcoholism. Expert Opin Pharmacother 2006 7( I 7):234I-2353.

32. Pettinati HM, Rabinowitz AR: Choosing the right medication for the treatment of alcoholism. Curr Psychiatry Rep 2006, 8(5):383-388

33. Gortelmeyer $\mathrm{R}$, Erbler $\mathrm{H}$ : Memantine in the treatment of mild to moderate dementia syndrome. A double-blind placebocontrolled study. Arzneimittelforschung 1992, 42(7):904-9|3.

34. Maler JM, Esselmann H, Wiltfang J, Kunz N, Lewczuk P, Reulbach U, Bleich S, Ruther E, Kornhuber J: Memantine inhibits ethanolinduced NMDA receptor up-regulation in rat hippocampal neurons. Brain Res 2005, I 052(2): 156-162

35. Holter SM, Danysz W, Spanagel R: Evidence for alcohol anti-craving properties of memantine. Eur J Pharmacol I996, 3 I 4(3): R I-2.

36. Bachteler D, Economidou D, Danysz W, Ciccocioppo R, Spanagel R: The effects of acamprosate and neramexane on cue-induced reinstatement of ethanol-seeking behavior in rat. Neuropsychopharmacology 2005, 30(6): I 104- III0.

37. Bachteler D, Spanagel R: Glutamatergic compounds: a perspective. In Drugs for Relapse Prevention for Alcoholism Edited by: Spanage R, Mann KF. Basel: Birkhäuser Verlag; 2005:205-2I6.

38. Piasecki J, Koros E, Dyr W, Kostowski W, Danysz W, Bienkowski P: Ethanol-reinforced behaviour in the rat: effects of uncom petitive NMDA receptor antagonist, memantine. Eur J Pharmacol 1998, 354(2-3): 135-143.

39. Escher T, Call SB, Blaha CD, Mittleman G: Behavioral effects of aminoadamantane class NMDA receptor antagonists on schedule-induced alcohol and self-administration of water in mice. Psychopharmacology (Berl) 2006, I 87(4):424-434.

40. Bisaga A, Evans SM: Acute effects of memantine in combination with alcohol in moderate drinkers. Psychopharmacology (Berl) 2004, I 72(I): 16-24.

41. Krupitsky EM, Neznanova O, Masalov D, Burakov AM, Didenko T, Romanova T, Tsoy M, Bespalov A, Slavina TY, Grinenko AA, et al.: Effect of memantine on cue-induced alcohol craving in recovering alcohol-dependent patients. Am J Psychiatry 2007, 164(3):519-523.

42. Evans SM, Levin FR, Brooks DJ, Garawi F: A pilot double-blind treatment trial of memantine for alcohol dependence. Alcohol Clin Exp Res 2007, 3 I (5):775-782.

43. Zarate CA Jr, Singh JB, Quiroz JA, De Jesus G, Denicoff KK, Luckenbaugh DA, Manji HK, Charney DS: A double-blind, placebo-controlled study of memantine in the treatment of major depression. Am J Psychiatry 2006, I 63(I): I53-I55.

44. Muhonen LH, Lonnqvist J, Juva K, Alho $\mathrm{H}$ : Double-blind, randomized comparison of memantine and escitalopram for the treatment of major depressive disorder comorbid with alcohol dependence. J Clin Psychiatry 2008, 69(3):392-399.

45. Anton RF: Obsessive-compulsive aspects of craving: development of the Obsessive Compulsive Drinking Scale. Addiction 2000, 95(Suppl 2):S2II-2I7.

46. Saunders JB, Aasland OG, Babor TF, de la Fuente JR, Grant M: Development of the Alcohol Use Disorders Identification Test (AUDIT): WHO Collaborative Project on Early Detection of Persons with Harmful Alcohol Consumption-II. Addiction 1993, 88(6):79|-804.

47. Aalto $M$, Tuunanen $M$, Sillanaukee $P$, Seppa K: Effectiveness of structured questionnaires for screening heavy drinking in middle-aged women. Alcohol Clin Exp Res 2006 , 30( I I): 1884- I888.

48. Gual A, Segura L, Contel M, Heather N, Colom J: AUDIT-3 and AUDIT-4: effectiveness of two short forms of the alcohol use disorders identification test. Alcohol Alcohol 2002, 37(6):591-596.

49. Poikolainen K, Karkkainen P: Diary gives more accurate information about alcohol consumption than questionnaire. Drug Alcohol Depend 1983, I I(2):209-216.

50. Goldstein BI, Diamantouros A, Schaffer A, Naranjo CA: Pharmacotherapy of alcoholism in patients with co-morbid psychiatric disorders. Drugs 2006, 66(9): | 229-| 237.

5I. Berglund M, Thelander S, Salaspuro M, Franck J, Andreasson S, Ojehagen A: Treatment of alcohol abuse: an evidence-based review. Alcohol Clin Exp Res 2003, 27(1 0): I645-1656.

52. Nunes EV, Levin FR: Treatment of depression in patients with alcohol or other drug dependence: a meta-analysis. JAMA 2004, 29 I (I 5): | 887- | 896

53. Moak DH, Anton RF, Latham PK, Voronin KE, Waid RL, DurazoArvizu R: Sertraline and cognitive behavioral therapy for depressed alcoholics: results of a placebo-controlled trial. J Clin Psychopharmacol 2003, 23(6):553-562.

54. Dawson DA, Grant BF, Stinson FS, Chou PS, Huang B, Ruan W]: Recovery from DSM-IV alcohol dependence: United States, 200I-2002. Addiction 2005, I 00(3):28I-292.

55. Vaillant GE: A 60-year follow-up of alcoholic men. Addiction 2003, 98(8): |043-|05|.

56. Heinala P, Alho H, Kiianmaa K, Lonnqvist J, Kuoppasalmi K, Sinclair JD: Targeted use of naltrexone without prior detoxification in the treatment of alcohol dependence: a factorial doubleblind, placebo-controlled trial. J Clin Psychopharmacol 200I, 2 I (3):287-292.

57. Muhonen LH, Lönnqvist J, Lahti J, Alho $\mathrm{H}$ : Age at onset of first depressive episode as a predictor for escitalopram treatment of major depression comorbid with alcohol dependence. Psychiatry Res 2008 in press. 